Tugas Besar Individu

\title{
PENERAPAN TATA KELOLA TEKNOLOGI INFORMASI DENGAN MENGGUNAKAN COBIT FRAMEWORK 4.1 ( STUDI KASUS PADA AMELIA HOTEL BANDAR LAMPUNG )
}

\author{
Nathanael Eucaris Ndoen \\ 1611050047 \\ Fakultas Bisnis \&Komputer \\ IIB Darmajaya Lampung \\ nael.1611050047@mail.darmajaya.ac.id
}

\begin{abstract}
Abstrak
Penelitian ini membahas tentang pentingnya Tata Kelola Teknologi Informasi, karena peningkatan peran Teknologi Informasi nantinya harus berbanding lurus dengan investasi yang dikeluarkan. Investasi Teknologi informasi biasanya mengeluarkan uang dalam jumlah besar. Untuk itulah diperlukan adanya tata kelola tata kelola Teknologi Informasi yang baik pada suatu perusahaan, agar investasi yang dikeluarkan tidaklah sia-sia dan memberikan manfaat yang diinginkan oleh perusahaan. COBIT framework menyediakan ukuran, indikator, proses dan kumpulan praktik terbaik untuk membantu perusahaan optimal dari pengelolaan Teknologi Informasi yang pantas bagi suatu organisasi. Dengan demikian maka dilakukan penelitian di Amelia Hotel Bandar Lampung menggunakan COBIT 4.1
\end{abstract}

Kata kunci : COBIT, COBIT 4.1, Tata Kelola Teknologi Informasi, Amelia Hotel Bandar Lampung

Abstract

This research aims to discusses the important of Information Technology Governance, due to increasing role Information Technology will be directly proportional to the investment incured by company. The investment for Information Technology usually spend large sums of money. For that reason it is necessary that the company should have a good IT Governance for make sure that the investment will be giving an advantage to company. COBIT Framework provide a measure, indicators, processes and collection of best practices to help companies optimize the management of Information Technology. Therefore we doing the research at Amelia Hotel Bandar Lampung by using COBIT 4.1

Keywords : COBIT, COBIT 4.1, IT Governance, Amelia Hotel Bandar Lampung 
Tugas Besar Individu

\section{PENDAHULUAN}

Kemajuan solusi yang nantinya akan didapatkan dari teknologi informasi dan juga pemanfaatannya terus meningkat dari waktu ke waktu, kecepatan dan keakuratan informasi akan menjadi tuntutan dalam menjalankan roda perekonomian baik oleh pelaku bisnisnya sendiri maupun oleh masyarakat dan juga pemerintah. Penerapan teknologi informasi pada proses bisnis perusahaan dipandang sebagai salah satu solusi yang nantinya akan dapat meningkatkan tingkat persaingan perusahaan. Penggunaan teknolgi informasi pada suatu perusahaan tentu nya juga akan membawa banyak keuntungan bagi perusahaan itu sendiri. Peningkatan peran teknologi informasi nantinya harus berbanding lurus dengan investasi yang dikeluarkan yang biasanya mengeluarkan uang dalam jumlah besar. Hal ini akan membutuhkan perencanaan yang matang dalam pelaksanaan investasi teknologi informasi nantinya. Untuk itulah diperlukan adanya tata kelola teknologi informasi yang baik pada suatu prusahaan dimulai dari perencanaan sampai dengan implementasi agar perusahaan tersebut dapat berjalan secara optimal. Tata kelola teknologi informasi mempunyai banyak sekali tools, salah satunya adalah COBIT. COBIT framework menyediakan ukuran, indikator, proses dan kumpulan praktik terbaik untuk membantu perusahaan optimal dari pengelolaan teknologi informasi dan mengembangkan pengendalian terhadap manajemen teknologi informasi yang pantas untuk suatu organisasi. Dengan demikian perusahaan akan merasa bahwa investasi teknologi informasi mereka membawa keuntungan maksimal bagi proses bisnis mereka. Amelia Hotel merupakan salah satu hotel bintang 4 di Bandar Lampung. Amelia Hotel menerapkan teknologi informasi sebagai salah satu cara untuk mencapai tujuan bisnis dari perusahaan tersebut. Agar investasi untuk teknologi informasi yang telah dikeluarkan oleh perusahaan sebanding dengan tujuan yang akan dicapai perusahaan, sudah tentu perusahaan harus menerapkan Tata kelola teknologi informasi yang baik. Dari uraian informasi dan masalah yang terjadi diatas, maka penulis tertarik untuk melakukan penelitian yang dapat saya tuangkan dalam bentuk jurnal dengan judul "PENERAPAN TATA KELOLA TEKNOLOGI INFORMASI DENGAN MENGGUNAKAN COBIT FRAMEWORK 4.1 (STUDI KASUS PADA Amelia Hotel Bandar Lampung 


\section{LANDASAN TEORI}

\section{Tata Kelola TI}

Menurut IT Governance Institute (ITGI) Tata kelola TI merupakan tanggung jawab dari pimpinan puncak Dan eksekutif manajemen dari suatu perusahaan. Dijelaskan pula bahwa Tata kelola TI merupakan bagian dari pengelolaan perusahaan secara keseluruhan yang terdiri dari kepemimpinan dan struktur organisasi dari proses yang ada adalah untuk memastikan kelanjutan TI organisasi dan pengembangan strategi dan tujuan organisasi.

\section{Kerangka kerja Tata Kelola TI}

Kerangka kerja tersebut memiliki peran dan fungsi masing - masing dalam Tata Kelola TI. Peran dan fungsi utama dalam Tata Kelola TI mencakup dua hal utama, yaitu : pengaturan (govern) dan pengelolaan (manage). Pengaturan (govern) mencakup hal - hal apa yang mendasari tata kelola tersebut yang ditentukan melalui pendefinisian strategi dan kontrol. Contoh kerangka kerja yang masuk dalam cakupan ini adalah COBIT. Adapun bagaimana tata kelola tersebut dilaksanankan merupakan cakupan dari pengelolaan (manage) yang ditentukan melalui rencana taktis dan eksekusi. Lebih jauh lagi, strategi dan kontrol yang masuk dalam cakupan pengaturan dipenuhi dengan penentuan kebijakan dan standar TI. Kebijakan tersebut merupakan pernyataan level tertinggi dan dapat digunakan sebagai acuan umum jika standar tidak tersedia. Standar sendiri ditentukan mengacu pada kebijakan dan menyediakan kriteria yang dapat digunakan untuk mengukur keakurasian dan efektivitas prosedur (mekanisme dilakukan sesuai dengan aturan yang ditetapkan).

\section{Tata Kelola Teknologi Informasi dan Tata Kelola Perusahaan}

Berdasarkan definisi tata kelola TI dari IT Governance Institute (ITGI) d Berdasarkan definisi tata kelola teknologi informasi dari IT Governance Institute (ITGI) dikemukakan bahwa tata kelola teknologi informasi adalah tanggung jawab dari dewan direksi dan manajemen eksekutif, oleh karenanya tata kelola teknologi informasi harus merupakan bagian yang tidak terpisahkan dari tata kelola perusahaan. Tata kelola perusahaan merupakan suatu sistem yang mengarahkan dan mengendalikan entitas-entitas pada suatu perusahaan. Ketergantungan bisnis akan suatu teknologi informasi telah membuatnya tidak dapat menyelesaikan isu tata kelola perusahaan tanpa adanya pertimbangan terhadap teknologi informasi. Sebagai gantinya teknologi informasi dapat mempengaruhi peluang strategi dan menghasilkan kritik atas perencanaan strategis yang telah dibuat. Dalam hal tersebut tata kelola teknologi informasi memungkinkan perusahaan untuk mengambil keuntungan maksimal atas informasi, dan juga merupakan penggerak tata kelola perusahaan. Hubungan antara tata kelola teknologi informasi dengan tata kelola perusahaan dapat dilihat pada gambar dibawah ini: Gambar 1 Hubungan Tata Kelola TI dan Tata Kelola Perusahaan

\section{COBIT Framework}

Control Objective for Information and related Technology, disingkat COBIT, adalah suatu panduan standar praktik manajemen teknologi informasi. COBIT dirancang sebagai alat penguasaan IT yang membantu dalam pemahaman dan memanage resiko, manfaat serta evaluasi yang berhubungan dengan IT. Standar COBIT dikeluarkan oleh IT Governance Institute yang merupakan bagian dari ISACA. Fokus proses COBIT digambarkan oleh model proses yang 


\section{Kerangka Kerja COBIT}

Untuk dapat memahami kerangka kerja COBIT, perlu diketahui bahwa COBIT mempunyai karateristik utama. Adapun karateristik utama dari kerangka kerja COBIT adalah fokus pada bisnis, orientasi pada proses, berbagi kontrol dan dikendalikan oleh pengukuran. Kerangka kerja COBIT secara keseluruhan dapat dilihat dalam gambar berikut

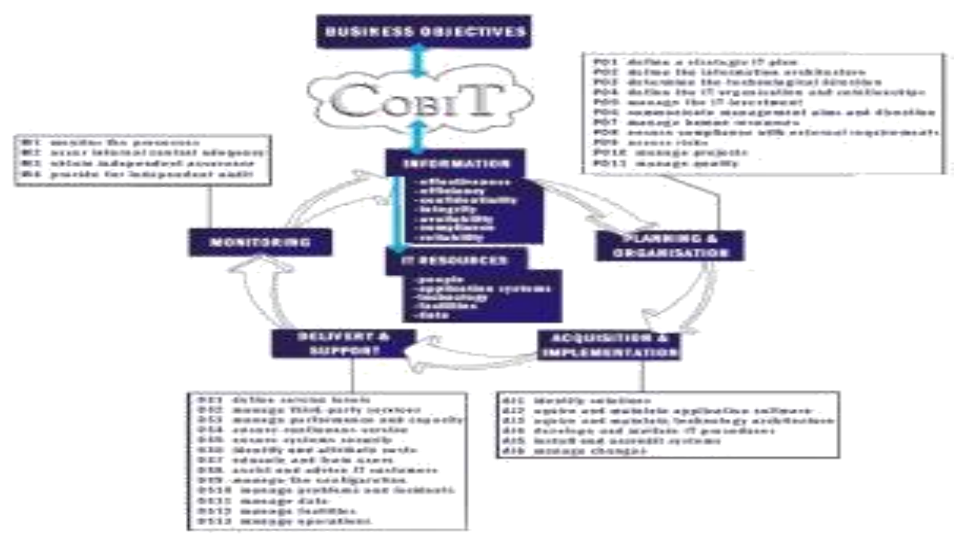

\section{Gambar Kerangka Kerja COBIT}

COBIT memiliki maturity level (Tingkat Kematangan). Model kematangan untuk pengelolan dan pengendalian pada proses pada teknologi informasi didasarkan pada metode evaluasi organisasi sehingga dapat megevaluasi sendiri dari level tidak ada (0) hingga optimis (5). Model kematangan dimaksudkan untuk mengetahui keberadaan persoalan yang ada dan bagaimana menentukan prioritas peningkatan. Model kematangan dirancang sebagai profil proses teknologi informasi, sehingga organisasi akan dapat mengenali sebagai deskripsi kemungkinan keadaan sekarang dan mendatang

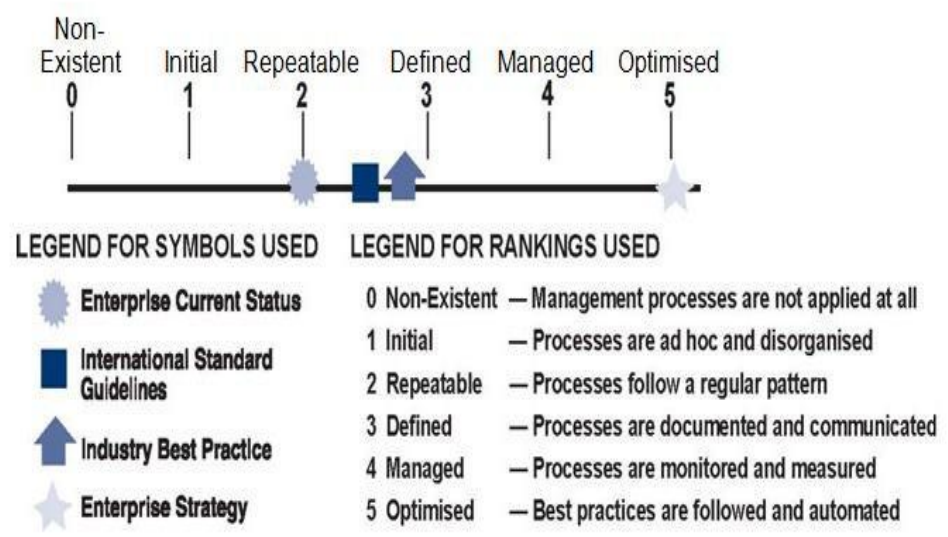

\section{Gambar : 2 Maturity Level}


Tugas Besar Individu

\section{METODOLOGI PENELITIAN}

Metodologi penelitian merupakan suatu metode yang digunakan untuk menentukan langkah-langkah yang harus dilakukan dalam sebuah penelitian. Di dalam metodologi penelitian yang harus mencerminkan keterkaitan langkah-langkah sehingga kegiatan menjadi lebih mudah, terarah, dan sistematis. Penelitian yang dilakukan menggunakan pendekatan kualitatif dengan metode studi kasus di Diskominfo Kota Bandar Lampung.

\section{Pendekatan Kualitatif}

Metode penelitian kualitatif adalah penelitian yang bermaksud untuk memahami fenomena tentang Hal apa yang dialami oleh subjek penelitian misalnya perilaku, persepsi, motivasi, tindakan, dll. Secara holistik, dan dengan cara deskripsi dalam bentuk kata-kata dan bahasa, pada suatu konteks khusus yang alamiah dan dengan memanfaatkan berbagai metode alamiah (Moloeng, 2004).

\section{Studi Pustaka}

Studi pustaka dilakukan dengan mengumpulkan beberapa teori, Metode ataupun model pada bidang manajemen sistem informasi atau TI pada umumnya, dan juga TI pada khususnya.

\section{Pengumpulan Data}

Dalam penelitian ini data yang dikumpulkan adalah data primer dan data sekunder. Data primer merupakan data yang didapat dari hasil wawancara dan kuisioner, sedangkan data sekunder merupakan data yang diperoleh dari beberapa laporan yang telah dipublikasikan oleh perusahaan

\section{Tahapan Penelitian}

Berdasarkan data yang telah dikumpulkan, maka kemudian data tersebut dianalisa dengan tahapan sebagai berikut

1. Identifikasi IT Goals

2. Identifikasi Business Goals

3. Identifikasi IT Process

4. Identifikasi Control Objectives

5. Maturity Level

\section{GAMBARAN LOKASI PENELITIAN}

Pada Tahun 2012 PT. Taman Mandiri mengakhiri kerjasama dengan PT. MGM (Metropolitan Golden Management) dan melakukan pergantian nama yakni Amelia Hotel Bandar Lampung pada tanggal 2 Februari 2013. Proses rebranding ini merupakan komitmen manajemen untuk lebih memahami dan mengerti kebutuhan pelanggan serta memberikan pelayanan terbaik kepada pelanggan.

Amelia Hotel Bandar Lampung terdiri dari 135 kamar yang dilengkapi dengan lantai parket, serta fasilitas penunjang lain nya yakni : Restaurant dan Bar (Golden Dragon Chinese Restaurant, 750Rasa Coffee Shop, Onyx Lounge, Brava Parlour, Executive Lounge), Business Centre. 
Tugas Besar Individu

\section{PEMBAHASAN}

\section{Identifikasi Business Goals}

Pada tahap ini akan di identifikasi business goals yang berlaku di COBIT 4.1 dan diselaraskan dengan tujuan bisnis dari perusahaan. Berikut adalah tujuan bisnis dari Amelia Hotel Bandar Lampung

Tabel 1 Hasil Pemetan Tujuan bisnis The Arista Hotel denganTujuan Bisnis COBIT

\begin{tabular}{|c|c|c|}
\hline Business goals COBIT & $\begin{array}{c}\text { Tujuan sasaran Amelia Hotel } \\
\text { Bandar Lampung }\end{array}$ & $\begin{array}{c}\text { Prespektif } \\
\text { business goals } \\
\text { COBIT }\end{array}$ \\
\hline $\begin{array}{l}\text { Improve and maintain business } \\
\text { proces functionality }\end{array}$ & $\begin{array}{c}\text { Menjadikan Amelia Hotel } \\
\text { Bandar Lampung sebagai } \\
\text { pilihan utama }\end{array}$ & Internal Prespektif \\
\hline $\begin{array}{l}\text { Improve and maintain business } \\
\text { proces functionality }\end{array}$ & $\begin{array}{c}\text { Menjadikan Amelia Hotel } \\
\text { Bandar Lampung sebagai hotel } \\
\text { yang berkualitas pada pelayanan }\end{array}$ & Internal Prespektif \\
\hline $\begin{array}{l}\text { Improve costomer orientation and } \\
\text { service }\end{array}$ & $\begin{array}{l}\text { Menciptakan pelanggan yang } \\
\text { loyal dan mejaga hubungan baik } \\
\text { dengan tamu maupun rekan }\end{array}$ & Customer Prespektif \\
\hline $\begin{array}{l}\text { Offer competitive produk and } \\
\text { service }\end{array}$ & $\begin{array}{c}\text { Memberikan pelayanan yang } \\
\text { kualitas terbaik pada tamu.Baik } \\
\text { dari segi kebersihan } \\
\text { kamar,kualitas makanan yang } \\
\text { terjamin bersih dan } \\
\text { enak,keamanan dan } \\
\text { kenyamanan }\end{array}$ & Customer Prespektif \\
\hline
\end{tabular}


Tugas Besar Individu

\begin{tabular}{|l|c|c|}
\hline $\begin{array}{l}\text { Improve and maintain operational } \\
\text { and staf produktif ,manage produk } \\
\text { and business inovation }\end{array}$ & $\begin{array}{c}\text { Menjaga sumber daya } \\
\text { Manusianya tetap professional } \\
\text { dengan di adakan training dan } \\
\text { juga menghasilkan } \\
\text { produk(kamar yang } \\
\text { bersih,makanan yang enak dan } \\
\text { pelayanan yang baik) }\end{array}$ & $\begin{array}{c}\text { Internal Prespekif,Learning and } \\
\text { Growth Prespektif }\end{array}$ \\
& & \\
\hline
\end{tabular}

\section{Identifikasi IT Goals}

Pada tahap ini akan di identifikasi business goals yang berlaku di COBIT 4.1 dan diselaraskan dengan tujuan bisnis dari perusahaan.

Tabel 2 IT Goals yang Teridentifikasi pada Amelia Hotel Bandar Lampung.

\begin{tabular}{|c|c|}
\hline 1 & Ensure satisfication of end users with service offerings and service levels. \\
\hline 2 & Create IT agility \\
\hline 3 & $\begin{array}{l}\text { Define how business functional and control requirements are translated in effective } \\
\text { and efficient automated solutions. }\end{array}$ \\
\hline 4 & Acquire and maintain integrated and standarised application system. \\
\hline 5 & Acquire and maintain an integrated and standarised IT infrastructure. \\
\hline 6 & Acquire and maintain IT skills that respond to the IT strategy. \\
\hline 7 & Ensure seamless integration of applications into business processes. \\
\hline 8 & Ensure proper use and performance of the applications and technology solutions. \\
\hline 9 & Make sure that IT services are available as required. \\
\hline 10 & Improve IT's cost-efficiency and its contribution to business profitablity. \\
\hline 11 & Deliver projects on time and on budget, meeting quality standards. \\
\hline
\end{tabular}




\section{Tugas Besar Individu}

\section{Identifikasi IT Process}

Tahapan selanjutnya adalah penetapan IT process yang sesuai dengan IT goals dan nantinya akan disesuaikan dengan studi kasus . adapun IT process yang sesuai dengan IT goals yang berlaku untuk studi kasus ini adalah:

Tabel 3 Proses - proses TI yang Teridentifikasi pada Amelia Hotel

\begin{tabular}{|l|l|}
\hline \multicolumn{1}{|c|}{ IT Process } & \multicolumn{1}{|c|}{ IT Domain } \\
\hline PO2,PO3,PO4,PO5,PO6,PO7,PO8,PO10. & Plan and Organise \\
\hline AI1,AI2,AI3,AI4,AI5,AI6,AI7. & Acquire and Implementation \\
\hline $\begin{array}{l}\text { DS1,DS2,DS3,DS4,DS6,DS7,DS8,DS10, } \\
\text { DS13. }\end{array}$ & Deliver and Support \\
\hline
\end{tabular}

\begin{tabular}{|l|l|}
\hline ME1, ME4. & Monitor and Evaluation \\
\hline
\end{tabular}

\section{Identifikasi Control Objectives}

Dari setiap COBIT IT process terdapat detailed control objective yang merupakan alat kontrol dari IT Process itu sendiri. Berdasarkan penelitian yang telah dilakukan. Terdapat 159 detailed control objective yang terdapat pada Amelia Hotel Bandar Lampung.

\section{Maturity Level}

Berdasarkan analisa dan tanya jawab terhadap kebijakan, prosedur, dan proses yang berkaitan dengan penerapan tata kelola TI pada Amelia Hotel Bandar Lampung maka didapatlah ukuran tingkat kematangan dari penerapan tata kelola TI tersebut yang berdasarkan framework COBIT 4.1 
Tugas Besar Individu

adasd

\section{Kesimpulan}

Berdasarkan hasil analisis, dapat dilihat bahwa tingkat kematangan secara keseluruhan proses TI pada Amelia Hotel Bandar Lampung berada pada skala rata - rata 2,74, ini merupakan nilai yang cukup baik bagi sebuah perusahaan dimana sudah ada prosedur namun belum sepenuhnya baku atau dilaksanakan.

Tabel 4 Tingkat kematangan dalam pengelolaan Amelia Hotel Bandar Lampung

\begin{tabular}{|l|l|}
\hline Domain & $\begin{array}{l}\text { Tingkat } \\
\text { kematangan }\end{array}$ \\
\hline PO (Plan and Organise) & 2,56 \\
\hline AI (Acquire and Implementation) & 2,67 \\
\hline DS (Deliver and Support) & 2,84 \\
\hline ME (Monitor and Evaluate) & 2,91 \\
\hline Rata - rata & 2,74 \\
\hline
\end{tabular}

- Pada Amelia Hotel Bandar Lampung terdapat 9 proses TI pada level Repeatable but intuitive, dan 18 proses pada level Defined.

- Berdasarkan hasil mapping antara business goals Amelia Hotel Bandar Lampung dan COBIT Framework 4.1, terdapat 27 IT process dan 159 detailed control objectives yang harus diperhatikan.

- Amelia Hotel Bandar Lampung belum mempunyai IT Plan dan standar Tata kelola TI yang baku.

\section{Saran}

Membuat dan mendokumentasikan kebijakan dan prosedur tentang seluruh proses dan tata kelola TI secara formal sebagai pedoman standar bagi seluruh pengguna dengan tetap memperhatikan manajemen risiko dan good corporate governance.Menentukan QA agar mutu dan integritas produk TI dapat lebih terjamin.

Perusahaan sebaiknya menggunakan pedoman tata kelola TI yang baik untuk dijadikan acuan tetap dan untuk melaksanakan pengukuran kinerja TI.Mempersiapkan SDM yang 
Tugas Besar Individu

memadai, melakukan transferpengetahuan dari ahli kepada staff untuk meningkatkan pengetahuan dan skill.

\section{DAFTAR PUSTAKA}

[1] Akmal, 2010, EDP Audit, Jakarta

[2] ITGI. (2007). Framework Control Objectives Management Guidelines Maturity Models

[3] Jogiyanto, Hartono 2005, Analisis dan Design, Andi Offset, Yogyakarta

[4] Junita, Evy. (2012). Audit Tata Kelola Teknologi Informasi dan Komunikasi Melalui Pendekatan Maturity Assesment Tools COBIT 4.1 : Studi Kasus Pada PT. Semen Gresik Persero, $T B K$.

[5] Kesumawardhani, D. R. (2012, 01). Evaluasi It Governance Berdasarkan COBIT 4.1 (STUDI KASUS DI PT TIMAH (PERSERO) Tbk), Tesis, UI, Depok

[6] Nugraha, Riza. (2012). Pengukuran Tingkat Kematangan Teknologi Informasi Dengan Menggunakan Kerangka Kerja COBIT 4.1 Studi Kasus Pada PT.XYZ, Tesis, UI, Depok.

[7] Purnomo, L. H., \& Tjahyanto, A. (2007). Perancangan Model Tata Kelola Ketersediaan Layanan Ti Menggunakan Framework Cobit Pada BPK-RI.

[8] Ramadhanty, Dwiani, Penerapan Tata Kelola Teknologi Informasi dengan Menggunakan COBIT Framework 4.1 (Studi Kasus Pada PT. Indonesia Power), Tesis, UI, Depok

[9] Sarno, Riyanarto 2009, Audit Sistem dan Teknologi Informasi, ITS, Surabaya

[10] Sembiring, S. W. (2013). Evaluasi Penerapan Teknologi Informasi

$$
\begin{array}{cllll}
\text { Menggunakan } & \text { Model } & \text { COBIT } & \text { Framework } 4.1 \text { (Studi } \\
\text { Kasus } & \text { PT. } & &
\end{array}
$$

Prudential Indonesia), Tesis, MTI, Universitas Atma Jaya, Yogyakarta 
Tugas Besar Individu 